\title{
ENTRE MODAS E MODALIDADES DA LIINGUA: O GÊNERO CONVERSA NO WHATSAPP
}

\section{BETWEEN FASHIONS AND MODALITIES OF THE LANGUAGE: THE GENRE CONVERSATION IN THE WHATSAPP}

\author{
GOMES, VITOR PEREIRA \\ PROFESSOR DE LETRAS DO IFSP-AVARÉ-SP \\ MESTRE EM LIINGUIISTICA E LIINGUA PORTUGUESA PELA FCLAR-UNESP/ARARAQUARA-SP \\ VITORPG9@GMAIL.COM \\ ORCID ID: HTTPS://ORCID.ORG/0000-0002-0710-7009
}

\section{ROZENFELD, CIBELE CECÍLIO DE FARIA}

PROFESSORA DO PROGRAMA DE PÓS-GRADUAÇ̃̃O EM LINGUÍSTICA E LÍNGUA PORTUGUESA

PELA FCLAR-UNESP/ ARARAQUARA-SP

PÓS-DOUTORA PELA UFSCAR/SÃO CARLOS-SP

CIBELEROZ@GMAIL.COM

ORCID ID: HTTPS://ORCID.ORG/0000-0001-8915-9541

\section{RESUMO}

Diálogos por meio da ferramenta Whatsapp vêm sendo amplamente praticados por pessoas no mundo inteiro, independentemente da idade e escolaridade. Este estudo analisa o gênero conversa no Whatsapp, objetivando entender a natureza de suas formas e sentidos para alunos em contexto de uma disciplina de pós-graduação. De natureza qualitativa, com procedimentos interpretativistas, foi feito, primeiramente, um levantamento bibliográfico de pesquisas sobre o Whatsapp. Tendo sido identificada uma lacuna em relação ao estudo do gênero produzido nesse ambiente, bem como do seu possível lugar no ensino, em meio a outras ferramentas de interação, é que se originou o presente estudo. Na sequência, considerou-se teóricos que analisaram as modalidades da língua, buscando compreender o lugar do virtual e sua importância em ambientes de ensino. A partir das considerações teóricas, analisou-se o discurso de uma conversa no Whatsapp, produzida por um grupo de alunos de pós-graduação, durante seis meses. Nos resultados, notam-se transposições, compensações e peculiaridades desse gênero de discurso em relação a outros, fato que, juntamente com sua crescente ocorrência em diferentes ambientes, justificam o estudo de sua tipologia. 
Palavras-chave: Gênero Conversa no Whatsapp; Modalidade de uso da língua; Ensino.

\section{ABSTRACT}

Dialogues using Whatsapp tool has been extensively practiced by people around the world, regardless of age and schooling. This study analyses the genre Whatsapp chat and aims to comprehend the nature of methods and meanings to students that took part in a postgraduate. It qualitative nature, with interpretative procedures, has been firstly a bibliographical survey about Whatsapp researchs. Having been identified a lack in relation to studies of the genre produced in this environment as well as of his place in teaching among others interactions tools, it originated this study. Following, it based on theorists who analyzed modalities of language, searching to comprehend the place of virtual in these modalities and his importance in a teaching environments. Starting from theoretical considerations, the conversation discourse in Whatsapp, produced by post-graduation students for six months. It was perceived recurrence of transpositions, compensation and peculiarities on this genre in relation to others, therefore, with his expanding ocurrence on different environments, it requires the typology's study.

Key words: Genre Whatsapp chat; Language usage modality; Teaching.

\section{INTRODUÇÃO}

As interações na cibercultura têm sido, cada vez mais, foco de interesse de pesquisadores ${ }^{1}$. Tal fato decorre, primeiramente, do desenvolvimento de recursos tecnológicos, como efeito dos "sistemas [virtuais] que estão em beta permanente, ou seja, sempre abertos" (BRAGA et al., 2017, p. 34). Em segundo lugar, pelas alterações nas relações sociais ocasionadas por elas, sendo uma delas, a emergência de gêneros de discurso.

No caso específico do Whatsapp, em 2020 (completados 11 anos de seu lançamento), já existem milhares de publicações a respeito de seus diferentes usos. Dentre elas, destacamos (devido ao seu grande número) as das áreas da Sociologia, das Ciências Médicas e da Linguística. Nessas duas últimas, o aplicativo é, quase sempre, estudado como ferramenta de

1 Tais como, LÉVY, 1999; HILGERT, 2000; MARCUSCHI, 2007; TORI, 2010; COUTINHO, LISBÔA, 2011; BRAGA, 2013; GÓMEZ CAMACHO e DEL CASTILLO, 2015; 2017; BRAGA, 2017; CAIADO e LEFFA, 2017; ÇETINKAYÁ et al., 2017; 2018. 
ensino, atingindo o total de pouco mais de 300 pesquisas $^{2}$. No entanto, encontramos também alguns (poucos) trabalhos que focalizaram a materialidade linguística como objeto de estudo (GÓMEZ CAMACHO e DEL CASTILLO, 2015; 2017; CAIADO e LEFFA, 2017; ÇETINKAYA et al., 2017 ; 2018) e nenhum trabalho foi encontrado que tenha se ocupado de analisar a Conversa no Whatsapp pelo viés dos estudos dos gêneros de discurso, fato que nos aponta para uma lacuna nos estudos da área.

Nessa perspectiva, o objetivo deste trabalho é trazer as formas e os sentidos do gênero "Conversa no Whatsapp", examinando suas marcas durante a interação entre alunos de um programa de pós-graduação, ao longo de sua participação em uma disciplina. As principais inquietações que nortearam o desenvolvimento do trabalho foram: como podem ser classificadas as diferentes formas de expressão linguística em uma conversa em contexto virtual (Whatsapp)? Trata-se de escrita, oralidade, ou uma nova modalidade? Quais as possibilidades dessa nova forma de comunicação para práticas de ensino?

A fim de responder a tais questionamentos, desenvolvemos a pesquisa que apresentamos nos próximos itens. Para tanto, estruturamos o texto em cinco itens: o primeiro, que consiste nesta introdução, expõe as pretensões e a organização do artigo. O segundo apresenta uma discussão teórica sobre os gêneros de discurso em práticas de letramentos, assim como sobre as Tecnologias Digitais de Informação e Comunicação (doravante TDICs) em contexto educacional. No terceiro item é apresentada a metodologia da pesquisa, incluindo a descrição do contexto da investigação. Por fim, no quarto item, apresentamos a análise do corpus, e trazemos, na sequência, as nossas considerações finais.

\section{PRÁTICAS SIGNIFICATIVAS DE LINGUAGEM NO ENSINO: OS ESTUDOS DOS GÊNEROS E OS GÊNEROS VIRTUAIS NO CONTINUUM ENTRE ORALIDADE E ESCRITA}

Estudiosos interessados em práticas significativas atentam-se à linha tênue entre aprendizagem e atividades sociais, por meio da criação de conexões entre um objeto de estudo e uma atividade humana. Nesse contexto, surgem os trabalhos com foco nos gêneros de discurso ${ }^{3}$.

2 Para obter tal resultado, colocamos em ferramentas de busca para periódicos e livros a palavra Whatsapp, bem como as especificações Educação e Ensino.

3 Existe uma diversidade na forma de se referir aos "gêneros" de um texto/discurso, sendo que alguns estudiosos priorizam o termo "gênero textual" (na Linguística Textual de Marcuschi, por exemplo), "gênero de discurso" (em estudos bakhtinianos) ou "gênero discursivo" (cf. Fanjul, 2012; Rojo, 2015). Fanjul se apoia na definição de Bakhtin (2008) e, em sua obra, traduzida para o espanhol, modifica o determinante preposicionado (do discurso) 
Precursor dessa compreensão de que os gêneros de discurso estão em todas as produções linguísticas e não apenas nas de natureza estética, Bakhtin os observa como um repertório de formas para produção de enunciados (orais ou escritos), às quais, incialmente, chamara "gêneros linguísticos" (BAKHTIN, VOLOCHÍNOV, 2006, p. 44). Mais tarde, o teórico se aprofunda nesses estudos desenvolvendo um capítulo completo em uma de suas obras. Nesse momento, denomina-os por "gêneros do discurso" e os definem como os "tipos relativamente estáveis de enunciados" (BAKHTIN, 2003, p. 262).

Uma vez que todo discurso ocorre por meio de gêneros e que estes estão classificados de acordo com uma relativa estabilidade formal e funcional, para demonstrar essa variabilidade, Bakhtin elabora três categorias, a saber, o "conteúdo temático", que se refere às proposições e está relacionado à pequena parcela de novidade no discurso, uma vez que está limitado pela "exauribilidade semântico-objetal" de cada esfera de atividade humana (BAKHTIN, 2003, p. 281); a "construção composicional", que é a ordenação estrutural a condicionar todo enunciado; e o "estilo", como "seleção dos recursos lexicais, fraseológicos e gramaticais da língua" (BAKHTIN, 2003, p. 261). Bakhtin dá uma atenção especial a este último, porque, segundo ele, nos gêneros rígidos, ou seja, naqueles em cuja forma está fortemente pré-estabelecida, um sujeito pode ganhar voz se utilizar, por exemplo, de epítetos em meio ao seu discurso. No estilo, portanto, encontram-se os elementos que servem para compensar as perdas que se têm na mudança de uma esfera ou de um suporte para outra(o).

Pode-se entender essa variabilidade de "conteúdo temático", "construção composicional" e "estilo" quando Weber observa que as esferas sociais (categoria que aproximamos a de "esferas de atividade humana" em Bakhtin), se dividiram por conflitos históricos e passaram a produzir suas "próprias leis internas" (WEBER, 2001, p. 231), motivo este que corrobora com o desenvolvimento de peculiaridades de formas e sentidos em cada gênero de discurso.

Embora diferentes esferas produzam diferentes formas, ao viver em sociedade, o sujeito atravessa de uma esfera para a outra e, desse modo, para Bakhtin, existe um "repertório de formas" que "cada época e cada

para um adjetivo (discursivo). Rojo (2015, p. 15), ao estudar os gêneros em seu percurso histórico, os define como "entidades que funcionam em nossa vida cotidiana ou pública, para nos comunicar e para interagir com as outras pessoas (universais concretos)". Diante disso, Bezerra (2017) propõe o uso apenas do termo "gêneros". Não pretendemos, neste trabalho, nos aprofundar em tal discussão. Optamos por fazer uma breve explanação sobre os principais autores que discorreram sobre os termos e, então, seguiremos pautando-nos na noção de gênero de discurso proposta por Bakhtin (1929; 1979). 
grupo" compartilha (BAKHTIN, VOLOCHÍNOV, 2006, p. 44) o que, nesse sentido, torna razoável a ocorrência de usos quase que semelhantes entre um gênero e outro, numa espécie mesmo de transposição.

Dessa relação de transposições, compensações e peculiaridades de formas e sentidos da língua entre as diferentes esferas é que os gêneros são entendidos como "correias de transmissão entre a história da sociedade e a história da linguagem" (BAKHTIN, 2003, p. 268). Assim, os gêneros são, também, fundamentais aos letramentos, sobretudo a partir da perspectiva bakhtiniana que os divide em primários e secundários ${ }^{4}$. Estes últimos, geralmente, são manifestados na escrita e desenvolvem a neutralidade do dizer. Nos primários, menos observados pelos letramentos, estariam as subjetividades mais expostas, dado que, comumente, eles aparecem pelo uso da fala (MARCUSCHI, 2007) e é nesse sentido que, Bakhtin (1999, p. 45) notou que a língua, na modalidade oral, tem o recurso da entoação ou sinais fonológicos, que caracterizam alguns efeitos de sentido.

A diferenciação entre oralidade e escrita origina-se na gramaticalização, que tenta organizar o uso em sistema fechado (BAKHTIN, 1999). Em outras palavras, o estudioso defende que a língua não se prende no tempo, mas é atualizada em cada uso, o que torna necessária a renovação ininterrupta de suas gramáticas. Convêm, portanto, conforme Marcuschi (2001), assumir um continuum entre as modalidades, no qual, ambas convivem e emprestam, entre si, seus elementos particulares.

Observando que o sujeito na sociedade utiliza diferentes formas da língua para se envolver mais ou menos, Marcuschi (2009, p. 208) afirma que estudar os gêneros é compreender o "próprio funcionamento social da língua" e, assim, os define como

[...] textos que encontramos em nossa vida diária e que apresentam padrões sociocomunicativos característicos definidos por composições funcionais, objetivos enunciativos e estilos concretamente realizados na integração de forças históricas, sociais, institucionais e técnicas. (MARCUSCHI, 2009, p. 155)

Nessa perspectiva, o autor propõe os conceitos de suporte, tipos textuais e domínio discursivo. O suporte é o espaço em que um gênero

4 Bakhtin (2003, p. 64) separa os gêneros em primários (cotidianos) e secundários (institucionais). 
se realiza, como uma folha, um livro ou um ambiente virtual. Os tipos textuais são organizações estritamente linguísticas, definidos por suas funções retóricas (MARCUSCHI, 2009): a narração, a argumentação etc. Os domínios discursivos são as diferentes instâncias sociais: religião, comércio, lazer etc.

Analisando o gênero, estaremos, conforme Marcuschi (MARCUSCHI, 2009, p. 149), analisando "texto e discurso e uma descrição da língua e visão da sociedade". Nesse sentido, os gêneros têm importante papel nos letramentos, uma vez que os últimos constituem "habilidades, conhecimentos e atitudes necessários ao uso efetivo e competente da leitura e da escrita nas práticas sociais que envolvem a língua escrita [...]" (SOARES, 2003, p. 891 apud. SOUZA et al., 2012, p. 60).

Souza (2011), ao refletir sobre a noção de letramento crítico, sustenta que o desafio do professor é estimular a autonomia do aluno para manipular as informações em produções de gêneros. Para ele, a prioridade está em formar sujeitos com responsabilidade pelas transformações na sociedade. Nesse sentido, Monte Mór (2012, p. 45) pressupõe o mundo com necessidades a serem assumidas pela escola, em processo complexo resumido em "ver, descrever, explicar". Assim, pesquisadores do campo dos letramentos ${ }^{5}$ alertam para a relevância de não se confundir atividade de letramento com uma simples tarefa de compreensão. Por exemplo, para "explicar" um discurso, não basta assimilar e reproduzir práticas sociais. Mais que isso, é preciso entender a complexidade com a qual ocorre determinado fenômeno (MONTE MÓR, 2009). Assim, a atividade se aproxima das práticas significativas de linguagem.

Em 2020, tais práticas estão bastante alicerçadas no uso de TDICs, as quais impactaram, nos últimos anos, fortemente na sociedade: nas formas de relações e até nos modos e nas concepções de ensinar. Os gêneros virtuais envolvem a multimodalidade, importante traço de integração do "eu" com o mundo contemporâneo. Há, também, o objetivo da educação contemporânea de levar os alunos a agirem e a serem. Sobre essas duas aprendizagens, a cibercultura tem como seu principal motor a inteligência coletiva, entendida como um construto colaborativo dos participantes de um Ambiente Virtual de Aprendizagem (doravante AVA) (LEVY, 1999). 
Ao nos remetermos aos gêneros virtuais, notamos que os Chats ou bate-papos online ${ }^{6}$, bastante usuais nas duas últimas décadas, já foram objeto de vários estudos (cf. por ex. CAIADO e LEFFA, 2017, MARCUSCHI, 2001, 2007; HILGUERT, 2000). Hilgert (2000) observou que seu uso se trata de uma prática virtual que se caracteriza como uma fala por escrito. Porém, nas relações do continuum, hoje nota-se, que

a escrita não consegue reproduzir muitos dos fenômenos da oralidade, tais como a prosódia, a gestualidade, os movimentos do corpo e dos olhos, entre outros. Em contrapartida, a escrita apresenta elementos significativos próprios, ausentes na fala, tais como o tamanho e tipo de letras, cores e formatos, elementos pictóricos [...] (MARCUSCHI, 2007, p. 17)

Shuman (1993, apud MARCUSCHI, 2001, p. 34) realizou um estudo de caso sobre uma prática de aprendizagem híbrida/blended. Nela, o AVA foi avaliado positivamente, pois era uma forma de complementação para as interações face a face. A autora afirma que a permissão de informalidades na comunicação com o interlocutor e o descompromisso com a norma padrão da língua em diálogos virtuais, são características próprias da língua falada, constituindo, assim, uma "transposição". Porém, grafias como "vc", "msm" e "tb"7 são, praticamente, impronunciáveis e, portanto, consideramos tratar-se de um fenômeno peculiar das novas interações.

Com temática mais próxima à de nosso trabalho, Caiado e Leffa (2017) publicaram um estudo sobre o gênero "debate" no aplicativo Whatsapp. Os autores observaram que os três tipos de linguagem materializados no texto, a saber, mensagem de texto, áudio e emoticons, passam por "mixagem nas interações". (CAIADO e LEFFA, 2017, p. 128). Nessa multimodalidade, ao contrário da "fala por escrito", proposta por Hilgert (2000), acerca da escrita dos chats, Caiado e Leffa (2017, p. 130) caracterizam os áudios do Whatsapp como "oralização da escrita".

Ainda com foco em textos no Whatsapp, Gómez-Camacho e Del Castillo $(2015 ; 2017)$, comparam a norma da escrita no aplicativo com a norma da escrita em textos acadêmicos, produzidos pelos mesmos

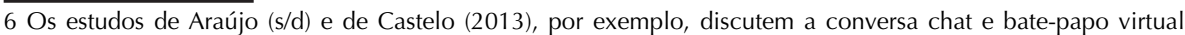
como gêneros. O primeiro encontra-se disponível em: <http://www.gelne.com.br/arquivos/anais/gelne2004/PDF/ J\%FAlio\%20C\%E9sar\%20Ara\%FAjo.pdf>, e o segundo em <https://revistas.pucsp.br/index.php/verbum/article/ view/15704>. Acessos em: 09 mar. 2020.

7 Você, mesmo e também, respectivamente. 
participantes. Os autores observam que, no aplicativo, os alunos se adequam à norma padrão muito próximo daquilo que fazem na escrita acadêmica.

Nos últimos trabalhos encontrados até 2020 acerca da temática, Çetinkaya et al., $(2017 ; 2018)$ estudam a perspectiva dos alunos, trazendo como ponto positivo desse ambiente a possibilidade de uso de imagens para ampliar a comunicação e para a expressão de opinião.

Portanto, concluímos a partir dessa revisão, que o Whatsapp, em seu atravessamento às mais diversas atividades humanas, já atingiu com intensidade o campo da pesquisa acadêmica, fato que contribuiu para que o aplicativo seja incluído nos projetos de ensino. Porém, há ainda uma lacuna no estudo de suas produções genuínas, ou seja, de um aprofundamento na tipologia do gênero Conversa no Whatsapp.

Nos próximos itens, traremos alguns elementos para a reflexão sobre as características dessa nova forma de comunicação, a Conversa no Whatsapp, com foco em premissas dos estudos dos gêneros. Porém, descreveremos, primeiramente, os procedimentos metodológicos deste estudo.

\section{PROCEDIMENTOS METODOLÓGICOS: O CONTEXTO, OS SUJEITOS E OS PROCEDIMENTOS}

Este trabalhoé de natureza qualitativa, tendo em vista seu objetivo de aprofundar a compreensão de um evento social (GERHARDT; SILVEIRA, 2009, p. 32), ou seja, a conversa em um ambiente virtual do celular (Whatsapp). Em relação aos procedimentos, trata-se de um estudo de caso (MEIRINHOS e OSÓRIO, 2010; ANDRÉ, 1995), na medida em que consiste na coleta, análise e interpretação de um caso contemporâneo da vida real, que é estudado com intensidade. A principal justificativa pela definição dessa estratégia de investigação está na facilidade de adequação a um fenômeno social novo.

O corpus analisado incide em um arquivo obtido a partir de uma conversa em grupo, realizada no aplicativo para smartphones Whatsapp. Tal aplicativo possibilitou que uma transcrição em formato doc. fosse enviada por e-mail aos autores, fato que permitiu análise minuciosa de todo o corpus. A "Conversa no Whatsapp" em foco durou seis meses, e ocorreu entre sete estudantes de uma disciplina, que se realizou no âmbito de um programa de pós-graduação de uma universidade pública do interior de São Paulo. Um dos autores deste artigo foi participante da interação, e da "Conversa". 
Destaca-se que a docente da disciplina explorou recursos de um ambiente virtual (na plataforma de gerenciamento de cursos Moodle ${ }^{8}$ ) e um presencial, com diferentes propósitos de ensino. O uso da plataforma Moodle teve o intuito de: 1 ) preencher lacunas temporais; 2 ) criar um espaço para compartilhamento de materiais (links, vídeos etc.); 3) aproximar os participantes por meio da interação assíncrona; 4) o aprofundamento dos temas tratados. ${ }^{9}$

Com esse intento, a docente utilizou sete ferramentas do Moodle $\mathrm{e}^{10}$ para diferentes fins. Ainda que de forma breve, a descrição desse ambiente será importante para caracterizar o contexto mais amplo do qual surgiu a prática, que é nosso objeto de análise.

Fóruns. Caracteriza-se por uma atuação mais livre. Nela, os participantes deram ênfase ao trabalho de trazer referências sobre materiais que eram vistos fora da disciplina, mas que dialogassem com ela.

Recursos. Usada pela professora para disponibilizar links de textos que estavam no programa da disciplina.

Tarefas. Com a orientação da professora, esse foi um espaço que serviu para os alunos postarem suas atividades individuais.

Wikis. Nela, os alunos tinham que postar uma questão norteadora por cada texto lido. As questões seriam lidas e debatidas nos encontros presenciais.

Chats. Essa ferramenta foi usada somente em uma aula e teve pouco acesso. Sua particularidade está no sincronismo das mensagens.

Diários. Usada pelos alunos para avaliar a disciplina no final do curso.

Pasta. Espaço no qual a professora disponibilizava os textos da disciplina.

Presencialmente (uma vez por semana) realizou-se: organização das atividades dos alunos, apresentação dos textos, discussão das questões norteadoras postadas na wiki, debate sobre textos, apresentação de palestra sobre objetos de aprendizagem por um convidado, e apresentação das propostas de artigos científicos.

8 O Moodle é um software que porta um sistema para criação e gerenciamento de cursos online. Seu desenvolvimento é colaborativo (contando com programadores, designers, administradores, professores e os próprios usuários) (MOODLELIVRE, 2008). Disponível em: <https://www.moodlelivre.com.br/tutoriais-edicas/974-o-que-e-moodle>. Acesso em: 17 mar. 2020.

9 Essa informação foi dada pela docente aos alunos em situação presencial do curso.

10 A versão da plataforma utilizada neste estudo foi a Moodle 3.0. 
Por sua vez, as atividades à distância (periodicidade fluida) foram: disponibilização dos textos no AVA (ferramentas: recursos, arquivo e URL); leitura individual dos textos; elaboração e postagem de questões norteadoras (ferramenta: Wiki); resenhas críticas (ferramenta: Tarefa); discussão dos textos em Fóruns; chat no Facebook (alunos e professora); artigo científico sobre a disciplina (ferramenta: Tarefa); discussão sobre objetos de aprendizagem (ferramenta: Fóruns), e a Conversa no Whatsapp - única prática que não contava com a participação da docente.

Para a análise da Conversa no Whatsapp, este trabalho está fundamentado em Braga (2013), sobre a língua escrita, e em Bakhtin (1999; 2003; 2006) e Marcuschi (2007), sobre oralidade e escrita ${ }^{11}$. A partir deles, tomamos como aspectos norteadores e seus respectivos estudos da teorias: (1) as regularidades formais das mensagens, pela relativa estabilidade dos gêneros; (2) os temas abordados, conforme as proposições que são permitidas; (3) o/a envolvimento/participação dos discentes, segundo as manifestações entoativas e de estilo; (4) os tamanhos e ajustes convencionados nas trocas de turno, considerando a construção composicional; (5) as transposições já descritas em outras comunicações, ou seja, aquilo que fora produzido de forma bastante similar a produções em outros suportes, segundo o repertório de formas da época e do grupo; (6) as compensações para manter relações típicas de outros suportes, outras esferas, como é o caso dos epítetos e; por fim, (7) as peculiaridades da linguagem do Whatsapp, dada a constituição de suas "leis internas". Todos esses elementos serão observados em conjunto, visto que suas recorrências se dão intrinsecamente nos excertos.

\section{O GÊNERO CONVERSA NO WHATSAPP: PECULIARIDADES, TRANS- POSIÇÕES E COMPENSAÇÕES}

A interface Whatsapp foi tomada pelos autores deste trabalho como foco de investigação devido à sua atualidade e abrangência, bem como, seu uso em contextos tão diversificados na atualidade. Nesta seção, faremos uma análise do corpus do grupo "Mídias S/A". A denominação foi indicada por uma aluna/participante que criou o grupo no qual se desenvolveu a conversa. Os subitens estão organizados segundo o instrumento metodológico apresentado anteriormente neste trabalho.

11 A explanação dos termos que trazemos para justificar os critérios e seus respectivos estudos teóricos encontram-se no item 2 deste artigo. Vale dizer que, como se pode observar dos critérios de análise, a estratégia de comparação entre o gênero Conversa no Whatsapp e outros gêneros está fundamentada sobretudo no método de Bakhtin em Estética da criação verbal: na obra, o filósofo russo sempre observa um gênero de determinada esfera em contraste com outro da esfera literária. 


\section{Regularidades formais e temas}

O primeiro tema abordado na conversa foi o uso da plataforma Moodle ${ }^{12}$, possivelmente, pela pouca familiaridade dos participantes com esse espaço. Para Souza (2011), um ambiente virtual possibilita exercício da autonomia dos alunos, que é expressa no compartilhamento de dúvidas com os colegas, reflexão sobre um problema e busca de soluções, além da tomada de responsabilidade, a qual verificamos no excerto a seguir, e que representa o início da conversa no grupo.

Laura $^{13}$ : Oi, gente! Eu passei um e-mail para a Cláudia [professora] ontem a noite pedindo o código [de acesso ao ambiente virtual], ainda não tive resposta. Assim que ela responder, passo para vocês.

Blenda: Muito obrigada, Lau! Posso te chamar assim? kkkkk

Laura: Claro! 14

Blenda: (영 : :

Laura: Vcs sabem qual o telefone do administrativo da pós?

O enunciado preambular de Laura representa nitidamente uma prática em espaço com intersecções da linguagem cotidiana com a acadêmica. Observa-se a vírgula antes de vocativo, letras maiúsculas nos começos de frases, acentuações e ausência de abreviação. Esse primeiro momento da Conversa aproxima-se do uso da língua escrita, que Braga (2013, p. 51) relaciona com uma forma mais "lapidada".

Ao utilizar um apelido como vocativo, seguido de um pedido de permissão e um código de risada (kkkkk), Blenda, pragmaticamente, desconstrói a formação imaginária que Laura fizera dela. Isso aparece já na resposta com o uso de um emoticon ${ }^{15}$, e se confirma em seguida, quando substitui a forma "vocês" que havia usado por sua abreviação Vcs. Sobre o uso do emoticon, ele pode ser explicado, primeiro,

12Convencionamos destacar em itálico as palavras que, neste item, utilizamos para nomear os temas das atividades.

13 Os nomes dos participantes, incluindo o da professora, são fictícios, a fim de preservarmos suas identidades. 14 Apesar de reconhecermos a importância dos emoticons neste gênero textual, não analisamos a fundo os sentidos por eles vinculados, primeiro, porque houve pouca ocorrência deles no corpus, segundo, porque reconhecemos a necessidade de estudo mais aprofundado em teoria semiótica para o desenvolvimento deste tipo de trabalho. As considerações que fazemos sobre eles são, portanto, interpretativistas e a partir dos teóricos que embasam nosso estudo.

15 Segundo Souza et al. (2012, p. 30), emoticom é um termo inglês que "une as palavras emotion e icon e significa 'ícone para emoção'". 
como variação da risada por estilo (MARCUSCHI, 2009) ou economia linguística e, segundo, como troca de afetividades (Blenda reproduz o mesmo emoticon que sua colega Laura havia figurado), fenômeno próprio de um ambiente "colaborativo" (LEVY, 1999).

Quanto às sequências tipológicas (MARCUSCHI, 2009), podemos observar variação por: injunção ("Oi"), narração ("Eu passei um e-mail para a Cláudia [professora] ontem a noite pedindo o código") e argumentação ("ainda não tive resposta"). No plano dos sentidos, essas três diferentes tipologias ampliam habilidades dos alunos no exercício do letramento (SOARES, 2003, apud SOUZA, 2012). Outro sentido, que ressoa na observação de Coutinho e Lisbôa (2011, p. 6), é a difusão da informação pelo ambiente: "Assim que ela responder, passo para vocês".

O início da interação é marcado pela situação de uso da língua, o domínio instrucional acadêmico (MARCUSCHI, 2009), com perfil hierárquico (graduados, mestres e doutores), que tende a estabelecer maior rigidez na forma (BAKHTIN, 1999) e aproximações à norma padrão da língua.

A alteração no tom revela a atualização da língua no uso (BAKHTIN, 1999) e pode, também, ser efeito da não inclusão da docente no ambiente. Aos poucos, no decorrer da conversa, misturaram-se características de um campo de estudo com as do lazer, o que é reafirmado pelo fato de que, após quinze meses de encerrada a disciplina, os membros continuaram participando das interações no grupo.

Assim, a intergenericidade marcada entre o diálogo (do domínio instrucional) e o bate-papo (do domínio do lazer), revela que o uso de gêneros não "tem uma relação biunívoca com formas textuais" (MARCUSCHI, 2009, p. 163). Na topologia bakhtiniana, por exemplo, ambos os gêneros encontram-se em extremos distintos: institucional versus cotidiano, secundário versus primário (BAKHTIN, 2003, p. 64).

Acreditamos que a não participação da docente favoreceu o surgimento de alguns temas como os denominados por nós de obstáculos e objeções. A manifestação de subjetividades vai aproximando a escrita do uso da fala (MARCUSCHI, 2007), sendo recorrentes as discussões de dúvidas sobre as atividades, bem como expressões de cansaço. Tais expressões refletem "movimentos interiores ${ }^{16 " ~(B A K H T I N, ~ 1999, ~ p . ~ 123) ~}$ dos alunos, ou seja, o desconforto ainda não expresso:

16 Os movimentos interiores, para Bakhtin (1999) formam uma tríade ao lado das palavras e das entoações. Os três associam-se, respectivamente, aos sentimentos, aos significados e aos sentidos que se encontram no "núcleo central sólido e durável da orientação social do indivíduo" (BAKHTIN, 1999, p. 123). Em outras palavras, são constructos, que embora internalizados, originaram-se das relações externas. 
Blenda: Gente, só eu que estou achando um pouco cansativa essa aula? rsrsrs

Blenda: Falar é mais fácil que digitar kkkkk

Carla: Naaaaaaao! (...)

Verônica: Uma,aliada!!

Esse diálogo ocorreu durante uma aula síncrona a distância e notase a partir dele que a meta/atividade também foi um dos temas tratados, conforme pode ser observado na fala de Blenda: "Falar é mais fácil que digitar kkkkk". Nessa mesma conversa, Blenda e Verônica também dialogaram sobre o tema cidades onde viveram, uma vez que ambas passaram pelo estado de Minas Gerais. Nota-se também, que, mais uma vez, os domínios instrucional e do lazer são entrecruzados.

Geralmente, nos aniversários dos membros, ocorriam os planejamentos para as confraternizações, tema que produziu muitas falas. A união factual que alunos e professora vivenciaram denota como o virtual age em colaboração para interações face a face (SHUMAN, 1993 apud MARCUSCHI, 2001).

Paralelamente ao desenvolvimento da disciplina, mas ainda aliado às atividades da Pós-graduação, o tema eventos acadêmicos também foi abordado na conversa. Discutiu-se ainda problemas pessoais, felicitações e greve dos funcionários da faculdade. Esse último tem um forte vínculo com o processo de letramento crítico (MONTE MÓR, 2012), pois o problema da comunidade é refletido criticamente pelos alunos.

Podemos concluir que os temas revelam a coexistência de esferas sociais: da interpessoal, da instrucional e das tecnologias virtuais. Assim, é possível notar a amplitude de espaços sociais e de tipos de interação favorecidos por esse espaço de comunicação. As formas e os sentidos confirmam as inter-relações síncronas entre enunciados (SAUSSURE, 2006) e entre a história da linguagem e a da sociedade (BAKHTIN, 2003).

Na próxima seção, seguem a caracterização das mensagens e a forma de participação dos interagentes.

\section{Envolvimento/participação, tamanhos das mensagens e ajustes con- vencionados}

Se os encontros presenciais aconteciam uma vez por semana, à distância, eles eram muito mais frequentes: na primeira semana, foram seis dias com a presença de, pelo menos, dois membros na Conversa no 
Whatsapp. Depois, o número variou entre três e cinco dias por semana. Os turnos eram, em geral, curtos, raramente, ultrapassando uma linha. Algumas vezes tinham apenas dois caracteres, mas também chegou a 318. Tal fato pode ser explicado, pela velocidade da escrita, com o texto de caráter informal e com facilidades do aplicativo (como sugestão e correção automáticas de palavras). Também, a coexistência de práticas virtuais é cada vez mais recorrente, na medida em que os celulares, como suportes, (MARCUSCHI, 2009) são cada vez mais leves, multifuncionais e de fácil transporte e acesso, facilitando, assim, o surgimento de uma escrita mais rápida e econômica.

A frequência nas discussões influenciou o desenvolvimento e o envolvimento dos alunos e contribuiu para o surgimento de temas que iam instigando-os a modificarem, refletirem sobre ou mesmo consolidarem seus projetos de pesquisa:

Carla: Gláucia, hoje da aula sai com tema pro pós doc

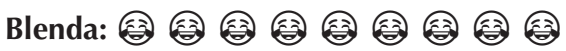

Carla: E ainda sobraram umas pesquisas pra você

Blenda: kkkkkkkkkkkkkk

Gláucia: Kkk... Se eu chegar em uma para o doutorado ta otimo!

Carla: Todos nós hein gente

Carla: Ta brotando ideia

Ainda que em tom de brincadeira dos participantes, infere-se que o grupo atuou nos participantes como motivador e fomentador de ideias para investigações.

Nesta seção é possível afirmar que houve uma intensa participação, propiciada pela facilidade de acesso. A participação contou com um estreitamento das relações. Por fim, de maneira geral, as mensagens foram curtas, com alta velocidade, devido desenvolvimento no aplicativo. No próximo subitem, a análise da tipologia da linguagem que se usa na Conversa no Whatsapp.

Transposições, compensações do suporte e peculiaridades do Whatsapp

A análise desta seção realizou-se por meio de uma classificação, presente no item 3, que tomou como fundamentos alguns autores 
que, sobretudo, se dedicaram à descrição dos usos da língua em suas diferentes modalidades, a saber, Braga (2013), Bakhtin (1999; 2003; 2006) e Marcuschi (2007).

No trecho "Laura: Obrigadaaaa / Blenda: Magina!", a interjeição Magina, redução de imagina, é uma transposição da fala. No entanto, dos 240 prolongamentos vocálicos (como Obrigadaaaa) no corpus, apenas 16 ocorreram na sílaba tônica, padrão da fala. Nas demais, aparecem na última sílaba. O tom entoativo logo antes do envio deve-se ao não acompanhamento sonoro, fato que distancia a escrita da oralidade. No entanto, as extensões não se restringem às vogais: "Gláucia: acabei de chega

!!! Obrigada Carla!!!" Os sinais de exclamação e interrogação sofrem extensões para marcar um reforço de humor.

O código de risada (como $k k k$ ) varia, seja como recurso de estilo ou elemento coesivo. No corpus, observou-se: 1 recorrência de hua; 4 de hehe; 6 de hsua; 12 de qua; 42 de rsrs; 106 de haha e 877 de $k k k^{17}$. A discrepância pode ser explicada pelos "estilos concretamente realizados" (MARCUSCHI, 2009, p. 179), e também por economia linguística, uma vez que a forma $k k k$ utiliza-se de apenas um tipo de caractere.

Em relação às abreviaturas, ocorreu: vc (você), tbm e tb (também), kd (cadê), ne (não é), ctz (certeza), blz (beleza), td (tudo), tds (todos), q (que), mto (muito), pq (porque), p (para), hj (hoje). Enquanto na escrita a abreviatura se forma, geralmente, pelo corte de uma parte final (exemplo: prof. de professor), na fala, apagam-se sílabas mais fracas em frases (exemplo: [ki ko so. fa'lo] de [o ke $\varepsilon$ ke o profe'so. fa'loo]. No virtual, a forma se dá, quase sempre, eliminando as vogais. Quanto às funções e sentidos, ora a abreviatura aparece como elemento coesivo (a), outrora como diminuidora do tempo de enunciação (b):

(a) Amanda: continuamos tendo aula normalmente mesmo que ela pergunte [...] acho $q$ ou a gente deixa as coisas num lugar e numa hora alguém tira ela da sala [...]

(b) Amanda: eu tb não consigo me concentrar... to igual cego em tiroteio.. ou surdo em bingo quauqua $m$ ta coisa ao $m s m$ tempo (grifos nossos)

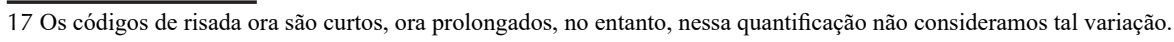


Amanda utiliza a palavra que e depois, abrevia em q, um recurso coesivo do uso. Depois, utiliza-se de três abreviaturas: a mensagem era enviada durante um encontro virtual, que ocasionou a necessidade de diminuir o tempo de enunciação.

Em "Vinicius: Oi, gente. Obrigado por me adicionarem :)", os caracteres ":)" são sinais gráficos da escrita. No corpus de Hilgert (2000) — um chat - é possível notar a presença de caracteres bem próximos, tais como ":-)". Trata-se de um caso de economia linguística temporal, marcada pelo desaparecimento de um caractere intermediário, além de ressonâncias carregadas pelos sinais gráficos, mesmo com a possibilidade de usar emoticons. Portanto, relações entre formas não ocorrem apenas nas modalidades, mas também, nas práticas sociodiscursivas.

Além das inovações tecnológicas, existem também as "denovações"18. Nos últimos anos, quase todos os smartphones foram substituindo as teclas de digitação por teclados touchscreen ${ }^{19}$. Manusear um teclado touch, no tempo de fala, tornou-se um problema para muitos. Por outro lado, as empresas lançaram os "sugestores de palavras ${ }^{20 "}$ e "corretores ortográficos", simultâneos à digitação, ferramentas que facilitaram a escrita, mas que (ainda) não foram feitas para algumas particularidades. No trecho "Carla: Pré ao / Carla: Perai" (espere aî), por exemplo, o corretor, programado na língua escrita normativa, entendeu que havia sido feita uma tentativa de se escrever "Pré ao" e fez a alteração.

A ausência de acentuação em "Vinicius: Tbm nao consegui...", provavelmente, está no fato de que os teclados exigem, pelo menos, duas ações a mais para que uma letra seja acentuada e os usuários não queriam perder tempo com isso, principalmente, na conversa informal. Cerca de cinco meses depois da Conversa no Whatsapp, essas ocorrências foram diminuindo e até desaparecendo. Não se trata, porém, de formalização da conversa e maior monitoramento, mas, de um desenvolvimento tecnológico, porque alguns disseram ter comprado aparelhos novos, que seguramente, aparecem com a opção do corretor ortográfico.

Neste item, observou-se que, como produto sócio-histórico, a linguagem produz um continuum entre transposições, compensações e

18 O geógrafo sueco Torsten Hägerstrand (1988 apud BURKE, 2002, p. 02) cunha o termo a partir da relação de que: se com o surgimento de uma tecnologia existe um lado positivo para o qual denomina-se "inovação", há sempre o outro lado, o negativo, pelo qual o chama "denovação".

19 Do inglês, "tela de tocar". Trata-se da tela com a capacidade de acionar o sistema do aparelho por toques, sem a necessidade de outro instrumento intermediário.

20 Termo proposto pelos autores deste trabalho, uma vez que não foi encontrada nomenclatura própria. Tratam-se de palavras que aparecem como uma sugestão simultânea para serem inseridas, com a necessidade de apenas um toque. Essas palavras são gravadas de um vocabulário interno do aplicativo e do histórico de termos que o usuário produziu. 
peculiaridades. Ocorreram no corpus: extensão vocálica ou de pontuação, sempre nos finais das palavras ou sentenças; códigos de risada, que variam tanto por estilo como por elemento coesivo; abreviações, que são feitas, geralmente, conservando as consoantes e, também, com funções de elemento coesivo ou diminuição do tempo de enunciação; casos de economia linguística e de ressonância no uso de caracteretas menores, numa preferência pontual em relação aos emoticons. Observaram-se alguns problemas técnicos que estiveram no início da Conversa, devido a falta dos "sugestores de palavras" e "corretores ortográficos". A seguir, as considerações finais.

\section{CONSIDERAÇÕES FINAIS}

A partir dos resultados desta pesquisa foi possível observar como a autonomia, a responsabilidade dos membros e a inteligência tecnológica se manifestaram e interrelacionaram no espaço virtual.

Notou-se a intergenericidade do virtual entre o domínio instrucional e o do lazer, e também, dos múltiplos espaços que o celular permite. Sobre os letramentos, a prática foi colaborativa no sentido de explorar tanto inquietações subjetivas, como problemas da comunidade em que participam.

Em relação às questões iniciais, é possível reafirmar a existência de três tipos de relações entre as discursividade. Primeiro, das transposições (pelo transporte de uma prática convencional para outra no ambiente virtual, sem perdas significativas): a extensão da pontuação como elemento entoativo, embora o uso pareça mais frequente nesse ambiente; e a economia linguística. Segundo, das compensações (na impossibilidade de transpor em diferentes ambientes, mas com a criação de alternativas que se corresponderam): a extensão vocálica como elemento entoativo, que no virtual ocorre pela última sílaba; e as abreviações feitas pela conservação das consoantes. Por fim, das peculiaridades (pela singularidade dos discursos no ambiente virtual): os códigos de risada, com uma variação genuína; e o uso de caracteretas e emoticons como elemento entoativo.

Concluímos que, quantas e quaisquer que sejam as modalidades, todas se relacionam, reiterando, assim, a participação do uso aqui estudado, no continuum notado por Marcuschi (2001).

Os traços peculiares serão um novo desafio para os estudiosos. Os autores deste trabalho não consideram como uma simples questão de suporte: não há somente uma transformação do lugar onde o texto 
é escrito, mas também das relações entre as pessoas, alcançando proporções macro das formas de cultura. Um exemplo disso foi a própria aprendizagem que relatamos neste artigo, com características de autonomia, colaboração etc.

\section{REFERÊNCIAS}

ANDRÉ, M.E.D.A. Etnografia da prática escolar. Campinas: Papirus, 1995.

ARAÚJO, J.C. (s.d.). A organização constelar do gênero chat. In: JORNADA - GELNE, XX., João Pessoa. Anais da XX Jornada - GELNE, pp. 1279-92. Disponível em: <http:// www.gelne.com.br/arquivos/anais/gelne2004/PDF/J\%FAlio\%20C\%E9sar\%20Ara\%FAjo. pdf>. Acesso em: 09 mar. 2020.

BAKHTIN, M.; VOLOCHÍNOV, V. (1929). Marxismo e filosofia da linguagem. São Paulo: Hucitec. 2006.

BAKHTIN, M. (1929). Marxismo e filosofia da linguagem, trad. Michel Lahud e Yara Frateschi Vieira. São Paulo: Hucitec. 1999.

(1979). Os gêneros do discurso. In:

Estética da criação verbal, trad.

Maria Ermantina Galvão G. Pereira. São Paulo: Martins Fontes. pp. 261-306. 2003.

BARBOSA, J.E. de A. (2009) Marcas de oralidade no texto escrito. Signum: estudos da linguagem, v. 12, $\mathrm{n}^{\circ} 1$, pp. 15-32. Disponível em: <http://www.uel.br/revistas/uel/index. php/signum/article/view/4174>. Acesso em: 14 mar. 2020.

BRAGA, D.B. Alguns Motivos para Alento: tecnologias a serviço dos professores. In: Ambientes Digitais. São Paulo: Cortez Editora, 2013, pp. 46-55.

BRAGA, J. de C.F.; GOMES JR, R.C.; RACILAN, M. (2017). Reflexões sobre ensino e aprendizagem de línguas na formação de professores via dispositivos móveis. Hipertextus Revista Digital, v.16, $\mathrm{n}^{\circ}$ 2, pp. 32-51. Disponível em: <http://www.hipertextus.net/ volume16/Art2Vol16.pdf>. Acesso em: 14 mar. 2020.

CAIADO, R.V.R.; LEFFA, V.J. (2017). A oralidade em tecnologia digital móvel: Debate regrado via Whatsapp. Hipertextus Revista Digital, v.16, n² 2, pp. 109-133. Disponível em: <http://www.hipertextus.net/volume16/Art6Vol16.pdf>. Acesso em: 14 mar. 2020.

CASTELO, A.S. (2013). Gênero textual virtual «bate-papo»: o funcionamento da língua e mediação. Verbum: cadernos de pós-graduação, n 5, pp. 71-80. Disponível em: <https:// revistas.pucsp.br/index.php/verbum/article/view/15704>. Acesso em: 14 mar. 2020.

COUTINHO, C.; LISBÔA, E. (2011). Sociedade da informação, do conhecimento e da aprendizagem: desafios para educação no século XXI. Revista de Educação. v. 18, nº 1, pp. 5-22.

CETINKAYA, L. (2017). The Impact of WhatsApp Use on Success in Education Process. 
International Review of Research in Open and Distributed Learning, v. 18, $\mathrm{n}^{\circ} 7$, pp. 59-74.

ÇETINKAYA, L.; SÜTÇÜ, S.S. (2018). The Effects of Facebook and WhatsApp on Success in English Vocabulary Instruction. Journal of Computer Assisted Learning, v.34, $\mathrm{n}^{\circ}$ 5, pp. 504-514.

GERHARDT, T.E.; SILVEIRA, D.T. Métodos de pesquisa. Porto Alegre: Editora da UFRGS, 2009.

GÓMEZ CAMACHO, A.; DEL CASTILLO, M.T.G. (2015). Escritura ortográfica y mensajes de texto en estudiantes universitarios. Perfiles educativos, v. 37, n 150, pp. 91-104.

. (2017). La norma escrita en las conversaciones de WhatsApp de estudiantes universitarios de posgrado. Revista Mexicana de Investigación Educativa, v. 22, $\mathrm{n}^{\circ} 75$, pp.1077-1094.

HILGERT, J.G.A construção do texto "falado" por escrito na Internet. In: PRETI, D. (Org.). Fala e escrita em questão. São Paulo: Humanitas, pp. 17-55, 2000.

LÉVY, P. Dilúvios. In: Cibercultura, trad. Carlos Irineu da costa. São Paulo: Editora 34, 1999.

LIMA-LOPES, R.E. de. (2017). Análise de registro e ciência das redes: estudando um grupo de Whatsapp dedicado à produção de cerveja artesanal. Hipertextus Revista Digital. v.16, n² 2, pp. 134-161. Disponível em: <http://www.hipertextus.net/volume16/ Art7Vol16.pdf>. Acesso em: 14 mar. 2020.

MARCUSCHI, L.A. Letramento e Oralidade no Contexto das Práticas Sociais e Eventos Comunicativos. In: SIGNORINI, I. (Org.) Investigando a relação oral/escrito e as teorias do Letramento. Campinas: Mercado de Letras, 2001. pp. 23-50.

. Oralidade e Letramento. In:

Da Fala para a Escrita: atividades de retextualização. São Paulo: Cortez, 2007. pp. 15-43.

. Produção textual, análise de gêneros e compreensão. São Paulo: Parábola, 2009.

MEIRINHOS, M.; OSÓRIO, A. (2010). O Estudo de Caso como Estratégia de Investigação em Educação. EDUSER: revista de Educação, Inovação, Investigação em Educação, vol. 2, $\mathrm{n}^{\circ}$ 2, pp. 49-65. Disponível em: < https://bibliotecadigital. ipb.pt/bitstream/10198/3961/1/O\%20estudo\%20de\%20ca-so\%20como\%20 estrat \% C 3 \% A 9 gia \% 20 de \% 20 investiga \% C 3 \% A $7 \%$ C 3 \% A 3 o \% 20 em \% 20 educa\%C3\%A7\%C3\%A3o.pdf>. Acesso em: 14 mar. 2020.

MONTE MÓR, W.M. O ensino de línguas estrangeiras e a perspectiva dos letramentos. In: BARROS, C.S. de; COSTA, E.G. de M. (Orgs.) Se hace caminho al andar: reflexões em torno do ensino de espanhol na escola. Belo Horizonte: Faculdade de Letras da UFMG, 
2012. pp. 37-50.

SAUSSURE, F. de. (1916). Curso de Linguística Geral, trad. Antônio Chelini, José Paulo Paes e Izidoro Blikstein. 33 ed., São Paulo: Cultrix, 2006.

SOUZA, A.L.S.; CORTI, A.P.; MENDONÇA, M. Letramentos no Ensino Médio. São Paulo: Parábola Editorial, 2012.

SOUZA, L. M.T.M. de. Para uma Redefinição de Letramento Crítico: conflito e produção de significação. In: MACIEL, R.F; ARAÚJO, V.A. (Orgs.). Formação de Professores de Línguas: ampliando perspectivas. Jundiaí: Paço Editorial, 2011, v. 1, pp. 131-137.

TORI, R. Educação sem distância: as tecnologias interativas na redução de distâncias em ensino e aprendizagem. São Paulo: Editora São Paulo, 2010. pp. 25-35.

Recebido em: 21/07/2020

Aceite em: 01/12/2020 